\title{
Quimioterapia en pacientes VHB positivos
}

\section{¿QUÉ ES EL VIRUS DE LA HEPATITIS B Y CUÁL ES SU EVOLUCIÓN?}

El virus de la hepatitis B (VHB) se adquiere a través de la vía vertical (madre-hijo), parenteral (pinchazos) o por vía sexual que afecta preferentemente al hígado produciendo una inflamación (hepatitis). La hepatitis aguda por VHB tiende a la curación espontánea pero bajo determinadas circunstancias se puede cronificar. En los casos en los que se cronifica se puede observar varias fases virológicas de evolución. Inicialmente el virus se replica en las células hepáticas sin causar daño hepático (fase de inmunotolerancia). Posteriormente, se activan los sistemas inmunes del paciente por lo que disminuirá la carga viral del paciente pero aparecerá inflamación hepática secundaria (es la fase de inmunoactividad). En algunos casos, esta actividad del sistema inmune es suficiente para mantener la carga viral indetectable sin daño hepático (fase de portador inactivo). Tras años de evolución, el sistema inmune puede incluso hacer desaparecer marcadores serológicos de infección crónica por VHB (hepatitis B pasada: anticuerpos frente al VHB) pero casi siempre se mantendrá parte del ADN del VHB en las células hepáticas (fase de VHB oculto).

A nivel mundial se estima que entre 350 y 400 millones de personas son portadoras inactivas del VHB. España se engloba dentro de los países de prevalencia intermedia $(1,2-2 \%$ de portadores inactivos y de un $20 \%$ de población con hepatitis B pasada). Sin embargo, tras la instauración de los programas de vacunación universal contra el VHB, la prevalencia ha disminuido (en el año 2007 los portadores inactivos de VHB eran de un $0,7 \%$ y de hepatitis B pasada de un $8,7 \%$ ). Estos porcentajes aumentan en grupos de edad más avanzada y en población inmigrante.

\section{¿QUÉ ES LA REACTIVACIÓN POR VHB Y CUÁL ES SU} IMPORTANCIA?

En ciertas situaciones de inmunosupresión, como el tratamiento con quimioterapia, hasta un $50 \%$ de los pacientes en fase de portador inactivo, y excepcionalmente los pacientes de una hepatitis B pasada (entre un 6 y 10\%), pueden sufrir reactivaciones del VHB caracterizadas por una elevación de la carga viral en sangre, la reaparición de los marcadores serológicos de hepatitis crónica y un incremento de las transaminasas. Estas reactivaciones suelen presentarse sin síntomas, aunque es frecuente que puedan derivar en una hepatitis clínica grave.

La reactivación en pacientes con tratamiento de quimioterapia provoca dos consecuencias importantes. Por un lado está el riesgo de desarrollar una hepatitis aguda grave con la consiguiente mortalidad asociada y, por otro lado, la reactivación se relaciona con la necesidad de retrasar o incluso suspender la quimioterapia, con el impacto clínico que puede suponer en la superviviencia total del los pacientes.

\section{¿QUÉ TRATAMIENTO QUIMIOTERÁPICO PUEDE PRO- VOCAR REACTIVACIÓN DE VHB?}

Cualquier agente quimioterápico podría ser susceptible de favorecer la reactivación de VHB debido a su efecto inmunosupresor sobre el sistema inmune. Sin embargo, los pacientes sometidos a tratamientos inmunosupresores más agresivos como es la quimioterapia asociada a corticoides o el tratamiento con rituximab presentan un riesgo aumentado de reactivación. Estos tratamientos se utilizan especialmente en enfermedades hematológicas.

\section{¿CÓMO SE PUEDE TRATAR LA REACTIVACIÓN POR VHB?}

En el caso de que se reactive el VHB, la primera medida debería ser la suspensión del tratamiento de quimioterapia pero esto puede disminuir la eficacia del tratamiento por lo que el oncólogo y el hepatólogo (o gastroenterólogo) deben considerar el riesgo y el beneficio de suspender el tratamiento antes de tomar cualquier decisión. La siguiente medida es comenzar con el tratamiento antiviral lo antes posible según indicación del médico.

\section{¿SE PODRÍA PREVENIR LA REACTIVACIÓN POR VHB?}

Para intentar evitar la reactivación y sus efectos desfavorables, todos los pacientes que van a ser sometidos a tratamiento de quimioterapia deben realizarse una serología para valoración del VHB.

Si el paciente tiene una serología negativa, debe vacunarse.

En caso contrario, debe ser remitido al hepatológo o gastroenterólogo para valoraración:

- Si el paciente cumple criterios de hepatitis crónica por el VHB debe ser tratado según indique el hepatólogo.

- Si el paciente se trata de un portador inactivo debe recibir tratamiento preventivo con antivirales frente al VHB (lamivudina, entecavir o tenofovir) desde 1 semana antes hasta 12 meses después de terminada la quimioterapia.

- Si por el contrario se trata de una hepatitis B pasada debe ser evaluado y, en función de la carga viral y del tipo de tratamiento inmunosupresor que va a recibir, será subsidiario de tratamiento preventivo.

Durante el tratamiento se deben controlar las transaminasas y la carga viral para evitar complicaciones.

Siguiendo estas recomendaciones se ha demostrado que se disminuyen tanto el riesgo de reactivación de $\mathrm{VHB}$ como de mortalidad por lo que si usted tiene una hepatitis B y va a comenzar con tratamiento de quimioterapia no dude en comunicárselo a su médico.

Beatriz Suárez Álvarez y José Luis Calleja Panero Servicio de Gastroenterología y Hepatología. Hospital Universitario Puerta de Hierro. Majadahonda, Madrid 